\title{
Contra la mercantilización pedagógica de los manuales de Lengua y Literatura: el caso de Ediciones del Eclipse (1994-2002)'
}

\author{
Against the Pedagogical Mercantilization of Language and Literature \\ Textbooks: the Case of Ediciones del Eclipse (1994-2002)
}

\author{
PAMELA VIRGINIA BÓRTOLI \\ Universidad Nacional del litoral- Instituto de Humanidades y Ciencias Sociales (UNL-CONICET) \\ Argentina \\ bortoli_p@hotmail.com \\ (Recibido: 05-06-2017; \\ aceptado: o6-IO-20I7)
}

Resumen. Esta presentación forma parte de una tesis doctoral en curso titulada "Género y Literatura en manuales para la escuela secundaria argentina (I984-20II)". Dicha investigación tiene como objetivo fundamental reconstruir el modo en que impac$\tan$ en los manuales de lengua y literatura publicados para el secundario argentino, discusiones en torno al género (gender) durante ciertos momentos históricos de inflexión.

Específicamente, este trabajo analiza las características de los manuales de lengua y literatura publicados a partir de la sanción de la Ley Federal de Educación en Argentina y explica las causas por las que existió una hiperproducción editorial sin precedentes. El artículo se detiene en un caso que se coloca a contramano de lo que venía sucediendo en el país: la editorial Ediciones del Eclipse. Concretamente, se hace foco en la publicación del manual Literator IV, escrito por Daniel Link, pues aborda la temática de los géneros y las sexualidades de modo novedoso.

Palabras clave: manuales de lengua y literatura; mercado editorial; del eclipse; Literator; género.
Abstract. This presentation is part of an ongoing doctoral thesis titled "Gender and Literature in manuals for Argentine secondary schools (1984-20II)." The main objective of this research is to reconstruct the ways in which discussions about gender, during certain historical turning points, impact language and literature textbooks published for secondary school in Argentina.

Specifically, this paper analyzes the characteristics of language and literature manuals published after the enactment of the Federal Law on Education in Argentina, and explains the reasons why there was an unprecedented editorial hyperproduction in those years. This article specifically analyzes the case of a publisher that, due to its particularities, is juxtaposed against what was happening in the country: the Eclipse Editorial. Particularly, the publication of the textbook Literator IV, written by Daniel Link, that deals with the issue of genres and sexualities in a groundbreaking way.

Keywords: school textbooks of language and literature; editorial Eclipse market; Literator; gender.

\footnotetext{
I Para citar este artículo: Bórtoli, Pamela Virginia (20I8). Contra la mercantilización pedagógica de los manuales de Lengua y Literatura: el caso de Ediciones del Eclipse (1994-2002). Alabe 18. [www.revistaalabe.com]

DOI: IO.I5645/Alabe20I8.I8.2
} 


\section{Contra la mercantilización pedagógica de los manuales de Lengua y Literatura: el caso Literator (1994-2002)}

A fines de I993, el entonces presidente Carlos Menem y el ex presidente Raúl Alfonsín firmaron en Argentina el denominado "Pacto de Olivos", un acuerdo polémico que aceptaba la reforma constitucional que tuvo lugar en I994. A partir de ésta, Carlos Menem quedó habilitado para presentarse en los comicios presidenciales de julio de I995, en los que fue reelegido, acompañado por Carlos Ruckauf como vicepresidente.

El segundo mandato de Menem estuvo caracterizado por dos factores que interesan para pensar en las políticas editoriales escolares en este país. En primer lugar, se dio una breve mejoría de las cuentas fiscales en el país, lo que convirtió a Argentina en un suelo confiable para los inversores globales; en momentos en que una masa de dólares circulaba por el mundo a la búsqueda de "mercados emergentes” más rendidores que los metropolitanos y por entonces retraídos (cf., entre otros, Romero, 200I; Bonnet, 2008; Galasso, 2OI4; Pucciarelli y Castellani, 2OI4; Bórtoli, 2OI7). Tuvo lugar, así, un proceso de extranjerización que también afectó al mercado editorial escolar a nivel mundial: el Grupo Carvajal absorbió la clásica editorial argentina Kapelusz (I994), Larousse se fusionó con Aique Grupo Editor SA (1998), se conformó en el país el Grupo Macmillan con la integración de los sellos Puerto de Palos y Editorial Estrada (2006), entre otras fusiones similares ${ }^{2}$.

En segundo lugar, el gobierno de Menem introdujo sin reservas las políticas recomendadas por el Banco Mundial en el ámbito educativo, ofreciendo una "propuesta modernizadora" que, si bien retomaba parte de la retórica desarrollista que articulaba educación y mercado, depositó en este último el papel de agente dinamizador y transformador. Según Tiramonti “de allí que la intervención del Estado aparezca rediseñada a la luz de la presencia dominante del mercado" (2004: 232).

Durante la segunda presidencia de Menem, se fortaleció el proceso de descentralización de la gestión educativa y disminuyó la inversión pública en educación. Además, se sancionó la Ley Federal de Educación No $24195^{3}$, que otorgó una oportunidad que el mercado aprovechó: los docentes se enfrentaban a nuevos desafíos sin haber sido preparados para ello, pues el país atravesaba una grave crisis económica que implicó la reducción presupuestaria para educación e imposibilitó brindar a los docentes las herramientas requeridas para la actualización.

\footnotetext{
${ }^{2}$ Se hace evidente aquí lo que afirma con muchísima claridad Cristian Molina en Relatos de mercado. Literatura y mercado editorial en el Conosur (1990- 2008) acerca de lo que sucedía en Argentina después de los 9o: “Si bien algunas editoriales independientes desaparecieron o se fusionaron a los grupos nacionales, otras nacieron (...) De este modo, mientras la lógica de funcionamiento de los Grandes Grupos es "estrictamente comercial", la de los sellos independientes es concebida como un medio para difundir ideas, arte y/o conocimiento, más que como empresas con fines de lucro". (2OI3: 55)

3 Entre las principales modificaciones, la LFE extendió la obligatoriedad escolar de siete a diez años, reestructurando los ciclos y niveles del sistema educativo. Así, se instituyeron los siguientes estamentos: la Educación Inicial (constituida por el Jardín de Infantes para niños de tres a cinco años de edad, con obligatoriedad para último año); la Educación General Básica (obligatoria, de nueve años de duración a partir de los seis años de edad); la Educación Polimodal (de tres años de duración como mínimo), en forma paralela a ésta, se ofrecieron Trayectos Técnico Profesionales con opciones de especialización laboral organizadas modularmente que la complementaban y otorgaban títulos técnicos. Los dos últimos niveles eran la Educación Superior y la Educación Cuaternaria para graduados (Ministerio de Cultura y Educación, I993).
} 
La instalación de la Carpa Blanca ${ }^{4}$ frente al Congreso fue el corolario de una serie de marchas y huelgas que los gremios docentes ya venían realizando y que encontraron una nueva forma de acción para reclamar un aumento de los fondos destinados a la educación. La medida fue muy popular, tanto así que durante los más de tres años (I997 a 2000) que la carpa estuvo instalada, los docentes recibieron más de tres millones de visitas, y apoyo público de personalidades que apoyaban las ideas de centro izquierda (Tiramonti, 2004; Puigróss, 2OIO, Bórtoli, 20I5). No obstante, el dinero estatal no llegó, los reclamos impulsados desde la Carpa Blanca no tuvieron eco y los docentes no fueron especializados a pesar del cambio de paradigma que implicó la sanción de la nueva Ley de Educación.

Estas dos variables hicieron que los manuales escolares publicados durante el segundo gobierno de Menem, se caracterizan por lo que Tosi (2OI5) denominó "mercantilización pedagógica”. Este concepto no significa que anteriormente las editoriales no se preocupaban por vender libros; sino que es en estos años cuando es posible asociar los manuales a una política editorial que considera al libro de texto haciendo hincapié en su faceta como mercancía, sujeta a las reglas del mercado: determinada por factores comerciales y desligada de toda supervisión estatal. Dice Tosi:

Hacia I983, un nuevo paradigma sociopolítico, económico y educativo trajo aparejada la implementación de otro tipo de política editorial, la de mercantilización pedagógica, que se caracteriza por la búsqueda de la mayor rentabilidad y la adecuación a los nuevos enfoques y diseños curriculares. Para lograrlo, las editoriales introdujeron contenidos novedosos y desplegaron nuevas estrategias para conformar un discurso en apariencia más dialógico y abierto; por ejemplo, la apelación directa al destinatario y la inclusión de discurso ajeno, entre otros. Asimismo, incorporaron nuevos conceptos y formas de tratamiento, que les han permitido circular exitosamente en el mercado escolar, pero que no siempre significaron un cambio genuino en las formas de concebir los objetos y los hechos. (20I3: 256)

Aunque Tosi sostiene que esta etapa inicia con la recuperación de la democracia, en I9835, se sostiene aquí que el verdadero auge de este modo de producción, comienza

\footnotetext{
${ }^{4}$ En abril de 1997 la Confederación de Trabajadores de la Educación de la República Argentina (CTERA) organizó una Carpa Blanca frente al Congreso de la Nación para pedir la derogación de la Ley Federal de Educación y la sanción de una Ley de Financiamiento Educativo. Así, mediante el símbolo de esta Carpa, se llevó adelante una de las protestas más extensas de la década de i99o en Argentina: propuesta llevada a cabo y sostenida por diversos sectores docentes, por numerosos contingentes de maestros ayunantes de todo el país que reclamaban un aumento en los fondos económicos destinados a la educación, la sanción de una Ley de Financiamiento Educativo y la derogación de la Ley Federal.

5 Todos los estudios realizados por Carolina Tosi son de una agudeza impecable y constituyen un aporte invaluable al campo de los estudios editoriales. Si bien ella caracteriza el periodo que va desde I983 a 2005 signado por la "mercantilización pedagógica", en la presente tesis subdividimos ese periodo en tanto las características más fuertes de ese modo de producción editorial aparecen a partir de la mitad de la década del 9o. No obstante, esto también es reconocido por Tosi, quien sostiene que "el surgimiento del Estado neoliberal marcó el cese de la hegemonía capitalista y se presentó como "la única opción" frente al agotamiento del Estado de bienestar, signado por un profundo desgaste y la ineficiencia del gasto público (...) La política de mercantilización pedagógica se vinculaba con el rol del Estado neoliberal y las funciones que se le comenzó a atribuir a la enseñanza en tanto transmisora de competencias (Grinberg y Levy, 2OO9: III) y garante de un saber hacer, cuyas bases quedaron sentadas en la Ley Federal de I993 y sus Contenidos Básicos Comunes." (2012: 7-8)
} 
a partir de la sanción de la Ley Federal de Educación y mediante el neoliberalismo, a mediados de los años 90.

En lo concreto, una de las consecuencias de esta mercantilización pedagógica fue la hiperproducción de manuales escolares por grandes empresas multinacionales como Santillana o Kapelusz. Otra de las derivaciones fue la variación en el modo de escritura de los libros: frente al objeto cuidado, con sello de autor o realizado en parejas pedagógicas, pensado por años como una serie por los mismos editores, surgieron manuales signados por la aparición masiva, la autoría numerosa y la producción constante de novedades que disponían de un corto lapso de circulación, acorde con los parámetros de productividad y rentabilidad ${ }^{6}$.

No obstante, la Editorial Del Eclipse, es un sello argentino que ofreció al mercado ciertos manuales escolares que escapaban de esta lógica mercantil y por eso nos interesa detenernos en esta propuesta. Nos referimos puntualmente al caso (Stake, I994) de Literator, una pareja de libros escritos por Daniel Link y publicados antes del ocaso de Del Eclipse como editorial escolar? ${ }^{7}$ Además, se intentará mostrar cómo esta colección logra escapar también de una matriz heteronormativa y sexista que caracterizaba a los manuales publicados hasta la fecha. Para ello, se ofrece la historización ${ }^{8}$ de la editorial, así como también el análisis de una serie de entrevistas y consultas ${ }^{9}$ (Mcgee Deutsch, 20I3) que se han realizado para triangular los datos obtenidos. Por último, se propone una lectura analítica de uno de los manuales de la serie: Literator IV. El regreso, pensado para el penúltimo año de la escuela secundaria argentina.

\footnotetext{
${ }^{6}$ Específicamente sobre el caso de Santillana, se recomienda el artículo: Bórtoli, P. (2OI7): “De libros como zapatos: la mercantilización pedagógica de los manuales de Lengua y Literatura publicados por Santillana (I994-20O2)". Quinto Coloquio de Avances de Investigaciones del Cedintel: Facultad de Humanidades y Ciencias, Universidad Nacional del Litoral. Santa Fe: Universidad Nacional del Litoral, en prensa.

7 La fundadora de Ediciones del Eclipse, Rosario Charquero, reflexionaba sobre esta situación y decía: "A partir del año I998, debido a la crisis económica en Argentina y a raíz de la irrupción de las empresas multinacionales en el mercado del libro de textos, con una presencia muy fuerte, comienza haber una modificación importante en el mercado que nos obligó a ubicarnos en un lugar que no estábamos en condiciones de afrontar. La modalidad de trabajo comenzó a modificarse: un libro en el año 2000 se consideraba novedad durante tres años, actualmente todos los años hay novedades en el libro de textos, con todo lo que eso conlleva, no solamente para las editoriales en el esfuerzo por producir contenidos nuevos año a año, sino también lo que produce en el público: los libros no pueden pasarse de mano en mano a lo largo de tres años porque de un año a otro el libro se modificó". (Gallardo 20O7) Por esta situación, si bien la editorial venía sobrellevando los embates acaecidos en la industria editorial durante los años 9o, ninguna de sus apuestas innovadoras pudo ir contra lo sucedido a partir de la crisis del 2OOI en nuestro país. En el plano de las editoriales pequeñas e independientes, como es el caso de Del Eclipse, debieron enfrentar los grandes cambios ocurridos en el mercado y adaptarse a la nueva situación. Fue así como, a partir del 2002, Ediciones del Eclipse dejó de producir libros de textos. Si bien mantuvo su identidad y la calidad de sus productos, la crisis del manual fue tan fuerte que debieron reorientar su trabajo hacia otro horizonte. Así, la editorial es reconocida actualmente por sus colecciones de literatura infantil, ya que ingresaron los libros álbum a nuestro país, encontrando una zona de vacancia en el mercado, que les permitió subsistir.

${ }^{8}$ Elsie Rockwell recurre a los aportes de Raymond Williams para explicar este término y sostiene:

¿qué significa historizar? Es claro que no equivale a describir la historia social de la escuela en diferentes cortes sincrónicos del pasado, si con ello se deja la impresión de que la cultura escolar corresponde a la norma vigente en cada momento. Historizar significa que encontremos en cualquier corte los sedimentos de periodos anteriores, así como los cambios que se anuncian antes de que queden inscritos en la norma oficial, es decir, buscar la coexistencia de saldos residuales y de prácticas emergentes, que se entrelazan con las tendencias dominantes en cualquier momento histórico. [Williams, I98I]" (2009: I65).

9 Para este punto, seguimos la distinción metodológica realizada por Sandra McGee Deutsch (2OI3) entre entrevista y consulta: la primera, grabada, con un protocolo a seguir que incluye la firma de un convenio sobre las condiciones de difusión; la segunda, más bien informal, puede o no ser grabada, puede darse en el seno de una conversación que reúna a más personas.
} 


\section{Sálvese quien pueda: el caso Del Eclipse}

Ediciones del Eclipse nació de la mano de Rosario Charquero, en pleno apogeo democrático: I989. Fue fundada como una empresa editorial dedicada a libros de textos escolares. En una entrevista que le realizaron hace algunos años atrás, la fundadora sostuvo:

La idea [de fundar Ediciones del Eclipse] nació como renovación de los contenidos de Lengua

y Literatura en la escuela media. Nosotros comenzamos con una propuesta cuyos contenidos fueron incorporados años posteriores por la reforma educativa del Estado. (Gallardo, 2007: 3)

Las propuestas innovadoras de este sello editorial encontraron un rápido eco en el público docente que compraba estos manuales para trabajar en el aula. Al respecto, recordó Itsvan Schirtter ${ }^{\mathrm{IO}}$ :

La editorial comenzó con los manuales de Lengua y Literatura, y más tarde con los de Matemática, los de matemática fueron posteriores y no fueron exitosos como los de lengua, innovadores y bellos sí, pero no exitosos. Los manuales tuvieron un éxito impresionante. A principios de año, cuando los docentes empezaban a planificar el año escolar, se armaban unas colas larguísimas de gente haciendo fila para comprar los manuales... (Bórtoli, 20I4b: 2).

Con la llegada de Santillana a nuestro Argentina, apenas recuperada la democracia, en los años 8o, la presencia de las estructuras multinacionales comenzó a hacerse sentir. Al respecto, también explicaba:

Los monopolios manualeros españoles, en los 9o, hicieron trizas toda posibilidad de que una pequeña empresa se dedique a hacer manuales... fíjate que desde entonces no hay empresas chicas que los hagan, porque es imposible competir con la distribución. Ni hablar desde la aparición de Tinta Fresca, con la que Clarín hizo tambalear hasta a Alfaguara... no se puede competir con semejante nivel de difusión...La problemática comenzó en los 9o, con la entrada de Alfaguara. De Santillana, en realidad. (Bórtoli, 20I4b: 2)

Las estrategias neoliberales que tuvieron lugar en nuestro país con el gobierno de Menem imprimieron a la educación la lógica de mercado también visible en el caso de Ediciones Del Eclipse. Esta lógica es caracterizada por la transnacionalización de los capitales que se dedican a esta actividad y su efecto es hartamente conocido: un deterioro profundo de los enunciados dirigidos a aprender y enseñar; y la formación de monopolios

Io Itsvan Schritter es ilustrador, escritor, diseñador y editor. Por su vinculación con Del Eclipse, recompone, a través de su palabra, la figura de Rosario Charquero, quien murió en 2011. 
editoriales que actúan principalmente en las escuelas. No obstante, Rosario Charquero disfrutaba la posibilidad que le proporcionaba ser una editorial independiente ${ }^{\text {I. }}$. En este sentido, manifestaba: "Una de las libertades es el placer que tenemos de poder hacer lo que deseamos, pero es muy difícil construir un espacio como editorial independiente cuando hay enormes estructuras multinacionales que compiten en todos los niveles de propuestas editoriales" (Gallardo, 2007).

Durante los años de producción de manuales ${ }^{\mathrm{I} 2}$, los específicos de Lengua y Literatura se caracterizaron por su originalidad. Tres colecciones salieron al mercado: por un lado, en I994 aparece reconocida serie Literator, compuesta por dos manuales pensados para los últimos años de la escolaridad secundaria y escritos por Daniel Link. Por otra parte, se prolonga y renueva la propuesta elaborada por Marta Lescano y Silvina Lombardo, con la serie Para comunicarnos, que incluía propuestas para $8^{\circ}$ y $9^{\circ}$ año y la posterior serie denominada Lecturas y escrituras que incluyó propuestas para toda la escolaridad.

Mientras que la primera serie constituye una novedad para el campo de la manualística, las series escritas por Marta Lescano y Silvina Lombardo se postulan más bien como un conjunto de soluciones prácticas a los docentes necesitados de nuevos consumos y productos reorientadores de su trabajo.

\section{Los manuales que rompieron el molde: los Literator}

Los manuales propuestos por Ediciones del Eclipse estuvieron signados por la actitud renovadora y desafiante. Un claro ejemplo son los elaborados por Daniel Link ${ }^{13}$, el reconocido catedrático argentino formado originalmente como Profesor de Castellano, Literatura y Latín, y especializado posteriormente en estudios literarios, en medio de la renovación teórica que tuvo lugar en nuestro país durante los primeros años de la década del 8o. Link fue alumno de Enrique Pezzoni y Beatriz Sarlo, entre otros reconocidos docentes. Además, se desempeñó como asesor editorial de Ediciones de la Flor y, desde I990 está a cargo de la Cátedra “Literatura del Siglo XX” de la carrera de Letras de la Facultad de Filosofía y Letras (UBA). Las producciones de Link reflexionan sobre la necesidad de resistir a las clasificaciones, entendidas como sistemas de clasificación cultural

\footnotetext{
II Entendemos que es un problema plantear el panorama editorial a partir de la polarización entre "grandes grupos / editoriales independientes". Como sostiene Santiago Venturini, este modo "constituye, por un lado, una disyuntiva marcada por un maniqueísmo que resulta negativo para definir al segundo polo, mucho más heterogéneo que el primero; por el otro, implica no registrar las diferentes apuestas, intereses y tomas de posición que se juegan en el interior del campo editorial y de ese conjunto ecléctico denominado "editoriales independientes". Es posible descomponer ese conjunto en una serie de rótulos: "pequeñas editoriales", "editoriales medianas", "microeditoriales" o incluso, como las llama el poeta y editor Daniel Durand (2OOI), "editorialcitas" (2OI4:3)". No obstante, la polarización es operativa en este momento.

${ }^{\text {I2 }}$ Si bien Ediciones del Eclipse no desaparece, debe reinventarse frente a la imposibilidad de competir con las grandes multinacionales: es conducida de modo obligatorio a una renovación de su perfil, a moverse para cubrir un nicho de mercado específico y alternativo, descuidado por los grandes grupos, como lo eran los libros álbum.

I3 Daniel Link es escritor y docente universitario en la Facultad de Filosofía y Letras de la Universidad de Buenos Aires.
} 
y antropológica: de qué manera eludir aquello que tiende a congelar y encorsetar (los géneros, la ciencia, el Estado, las sexualidades rígidamente definidas). En esa dirección, en la entrevista que se le realizó en el marco de esta tesis, al hablar acerca del objetivo principal que guiaba su trabajo de escritura, sentenció:

Yo venía de trabajar intensamente en el Ciclo Básico Común de la Universidad de Buenos Aires, lo que nos había servido para diagnosticar los principales déficits de la educación secundaria de aquel momento. El objetivo principal fue, pues, intervenir en la Escuela Media mediante la modernización de los contenidos y perspectivas analíticas relacionadas con el área de mi formación (principalmente la literatura, muy en segunda instancia la lengua). En el caso particular de (...) los Literator, [se trataba] de acercar la perspectiva del comparatismo a las aulas de la escuela media. (Bórtoli 20I4a: I).

Como es posible notar en las palabras de Link, se estaba al tanto de la modernización de los contenidos propuestos por la Ley Federal de Educación. No obstante, acerca de su consideración de las normativas oficiales emitidas por el ministerio, declaró: "Por supuesto que no [las tengo en cuenta]. Bastante hay que aguantarle al Estado como para encima tener en cuenta sus pesadillas pedagógicas.” (Link, 2OI4: 2). En esa línea, es central lo que se destaca en el libro desde sus portadillas: es una antología y una serie de actividades sobre literatura; es decir, se ubica a contramano de las propuestas de la época, signadas por la aparición de propuestas de manuales para el área "Lengua”, de acuerdo con lo propuesto por la Ley Federal de Educación y, más tarde, por los Contenidos Básicos Comunes. Con la formulación de estos documentos, la literatura pierde lugar en las aulas, puesto que los CBC eclipsaron los planteos renovadores de la teoría literaria con los enfoques lingüisticistas e instrumentalistas importados especialmente desde España: decisión que reforzó los supuestos aplicacionistas consolidados en buena parte del país promoviendo además una confusión extendida respecto de cómo y desde dónde enseñar a leer (Gerbaudo, 20Ir:I63).

No obstante estas determinaciones estatales, la recepción del público lector fue tan buena que el libro siguió reimprimiéndose hasta i997. En la tercera edición, se incluye una aclaración en la que el autor revela un gesto autobiográfico inusitado en los manuales escolares. Dice Link:

Escribí (es decir, armé, “edité”) Literator IV en la mitad del camino de mi vida. Todos los aciertos y los errores del libro tienen que ver con una manera de haber vivido, con una manera de haber hecho una "carrera académica" y, fatalmente, con un destino. (...) La perspectiva que he querido reivindicar en este libro supone, todavía, un cierto heroísmo, un cierto sistema de creencias, una cierta apuesta. (1994: vi)

E inmediatamente después, cita un fragmento de Escuela y Literatura (1983) de Roland Barthes en el que, entre otras cosas, se destaca el papel específico de la literatura en la escuela: 
El objetivo último es hacer temblar la diferencia (...) Hay que plantear las relaciones del sentido con "lo natural", asestado a las clases sociales por el poder y la cultura de masas, diré que la tarea de la escuela es impedir, si existe ese proceso de liberación, que la liberación pase por un retorno del significado. No hay que considerar nunca que las constricciones políticas sean un purgatorio en el que se debe aceptar todo. Al contrario, hay que poner en relieve siempre la reivindicación del significante para impedir el retorno de lo reprimido. No se trata de hacer de la escuela un espacio de predicación del dogmatismo, sino de impedir los rechazos. (1994a: vi)

Que el objetivo principal del manual sea "hacer temblar la diferencia” tiene amplísimas repercusiones. Perder el miedo a la crítica interna, aceptar que no hay premisas incuestionables, cuestionar las lógicas de la mercantilización pedagógica, entender que los valores no proceden del silenciamiento de la polémica; así como actuar en el reconocimiento de la complejidad que somos, constituyen claras apuestas del manual.

Particularmente en materia de género el texto intenta desarticular lo que Harold Garfinkel (ig67) llamó la "actitud natural”, es decir, una serie de axiomas incuestionables sobre el género, como por ejemplo: que es invariable, que hay sólo dos, que la dicotomía mujer/varón es natural, que los genitales son los signos esenciales del género, que ser femenina o masculino es natural, entre otros. El propósito del manual, entonces, tiene que ver con combatir esos presupuestos, desafiar su validez.

\section{Literator IV}

En este sentido, los Literator rompen el molde. Lo que no aparecía o apenas era mencionado en las propuestas analizadas anteriormente es puesto aquí en primera plana: cuerpos, sexo, prostíbulos, madres desleales, violaciones, bisexualidad... forman parte del todo innovador de la propuesta. Se analizarán en detalle estas cuestiones, atendiendo principalmente el caso del Literator $I V$, para poder ilustrar mejor estas particularidades. En primer lugar, vale decir que el libro se estructura de modo novedoso, ya que consta de cinco partes diferentes, pero articulables entre sí. En la primera de ella, titulada "Introducción” se recuperan brevemente algunos aspectos teóricos insoslayables para pensar la enseñanza de la literatura y que se pronuncian alrededor de lo que Link llama la "maldita pregunta”, a saber: ¿qué es la literatura? El autor propone entonces, reflexiones en torno a las categorías de institución, arte- artificio, uso- valor, personajes, autor, lengua ideología, lectura, entre otras. Asimismo, en esta sección se incluye una serie de actividades tendientes a incentivar el proceso creativo de los alumnos titulada Pequeño taller de escritura, pensado para "futuros grandes escritores" (I994: Xxi).

La segunda sección se divide en Unidades Temáticas: se alistan allí la mayoría de los textos literarios del manual, con actividades tendientes a problematizar las lecturas. Pero esas unidades resultan ya transgresoras. Los temas que se seleccionan son la patria, la guerra, el dinero, la familia y el erotismo. Frente a manuales que realizaban esta divi- 
sión mediante recortes temporales o tomando como ejes los diferentes tipos de texto, este planteo también es vigorosamente innovador. Mucho más si se atiende a los temas que se seleccionan, puesto que son principalmente los que otros manuales buscan decididamente evitar ${ }^{\mathrm{I}}$.

En la tercera parte, se halla una serie de actividades por época y periodo, atendiendo a las contextualizaciones que los textos citados requieren. Sigue luego una cuarta parte que detalla ciertas actividades por género (épica, cuento, novela, soneto, romances, entre otras) y, por último, aparece un encadenamiento de apéndices que completan la propuesta: un "diccionario de autores" es decir, una nómina de los escritores que aparecen en la antología, acompañada de una breve descripción biográfica; un índice de autores, otro de obras citadas y la bibliografía.

En términos de géneros y sexualidades, el texto resulta inverosímilmente novedoso, pues toca temas que no sólo no habían sido retomados por la tradición manualística, sino que seguirán silenciados mucho después. Por su parte, es especialmente interesante que los textos que conforman el corpus hayan sido escritos principalmente en la Antigüedad, la Edad Media, el Renacimiento y el Barroco. No obstante ese recorte, es posible el tratamiento y cuestionamiento de los valores tradicionales y la tematización de temas tabú.

Una de las cuestiones más novedosas tiene que ver con la presencia del cuerpo sexuado: la teta, el "bulto", el cuerpo todo será objeto de lectura y también de análisis. Por ejemplo, se incluye un fragmento de Gargantúa y Pantagruel titulado "El nacimiento" en el que Gargamella comienza con dolores de parto en plena borrachera con Grandgousier. En el momento del trabajo de parto, los personajes tienen este diálogo:

- ¡Ah sí!; para vosotros, los hombres, muy bien. Me contendré cuanto queráis; pero quiera Dios que os lo encontréis cortado.

- ¿El qué?

- Como no sois torpe, ya me entendéis.

- ¡Mi miembro!... Por la sangre de las cabras, si queréis haced que traigan el cuchillo.

- ¡Oh! Dios no lo quiera. Dios me perdone. No lo dije de corazón. No toméis en cuenta mis palabras. Bastantes trabajos estoy pasando hoy y todos a causa de vuestro miembro, que Dios conserve ante todo. (I994: 94)

\footnotetext{
${ }^{\text {I }}$ Sobre el modo en que los manuales mantienen una postura políticamente correcta, recomendamos el artículo de Carolina Tosi (2OI3): Huellas de lo políticamente correcto en libros de texto argentinos: la "modalización autonímica"”. Pragmática Sociocultural; Vol. I, Iss. 2, 25I-28I. [en línea]. Consultada el día 3o de noviembre de 2017 en http://museo.bn.gov.ar/media/page/carolina-tosi-ponencia.pdf. Allí se retoma a Courtine (2006) quien indaga la cuestión en los manuales escolares publicados en Estados Unidos. Lo políticamente correcto puede definirse como la reglamentación implícita o explícita de todo uso lingüístico que pueda ser considerado inapropiado por un determinado grupo y que, en consecuencia, domina las normas discursivas los manuales escolares. La consecuencia es que "la policía de las palabras, discreta y común, aparece desprovista de sujeto" (Courtine, 2006: I5I).
} 
Lo que en otro manual sería impensado es aquí parte del relato, incluido sin reservas. Es más, en otras actividades, incluso se hace foco en estas cuestiones: es el caso de unas preguntas sugeridas a partir de la lectura de dos textos de Luis de Góngora "Galatea descubre a Acis" y "A un sueño". En ambos aparece la palabra "bulto", en el primero de ellos haciendo referencia al volumen que ocupa Acis al esconderse de Galatea; en el segundo, como sinónimo de pene, en el marco de los sueños eróticos. Las actividades de post lectura son las siguientes:

a) ¿Cómo caracteriza Góngora al sueño erótico?

b) Comparar el uso de la palabra "bulto" en este poema [A un sueño] con el fragmento que lleva el número 83 [Galatea descubre a Acis]. (I994: I58)

Esta tematización del sexo aparece también mediante la recuperación de diversas escenas sexuales de textos literarios. Es el caso del anónimo "Romance de Gerineldo", en el que el padre encuentra a su hija teniendo sexo con su amante: "en el lecho se han metido, / y se hacen dulces halagos/ como mujer y marido:/ tantas caricias se hacen/ y con tanto fuego vivo, / que al cansancio se rindieron/ y al fin quedaron dormidos" (I994: I36).

Incluso el fragmento de Bocaccio titulado "Guillermo Rossiglione" que narra el modo en que un marido descubre la infidelidad de su esposa, asesina al amante y cocina su corazón para que la mujer lo cene. Además de lo polémico del argumento, las escenas sexuales son claras entre la mujer y el amante: “empezó a amarlo hasta el punto de que todo lo que él deseaba se lo otorgaba con sólo pedirlo y no pasaba mucho tiempo sin que se encontraran y se amaran con delirio" (I994: I54).

Las escenas sexuales aparecen en fragmentos teóricos usados para explicar algún tema, por ejemplo, se retoma parte de "Fragmentos de un discurso amoroso" en el que Roland Barthes sostiene "El corazón es el órgano del deseo (el corazón puede henchirse, desfallecer, etc., como el sexo)" (I994: I56) y también en explicaciones dadas por el mismo Link, acerca de cuestiones teóricas:

No cabría confundir, por otro lado, ese placer con el placer intelectual. El placer por conocimiento es, en varios sentidos, coincidente con el placer literario, pero puedo obtener conocimiento, por ejemplo, a partir de una conferencia. Puedo sentir placer por el conocimiento que obtengo a partir de una conferencia o de otra experiencia cualquiera (eso es un placer intelectual). El conocimiento da (a quienes nos lo da) un placer bárbaro. Pero el placer de la literatura es otra cosa. Digamos: es como la diferencia entre el sexo y el amor (diferencia que hasta Madonna conoce): sexo sería algo así como el conocimiento, el amor algo así como el placer estético. Y, ya que estamos, digamos: la coincidencia de las dos cosas, verdaderamente, es de lo mejor. Si este libro pudiera servir para suscitar ambos placeres, yo sería feliz, feliz de verdad. (I994: xviii) 
Toda esta explicación teórica se realiza antes de la existencia de la Ley 26r5o, sancionada y promulgada en octubre de 2006, que establece que todos los educandos del país tienen derecho a recibir Educación Sexual Integral, en establecimientos educativos públicos, tanto de gestión estatal como de gestión privada. Cuanto menos, el gesto de Link es vanguardista.

Por otra parte, Literator $I V$ intenta deconstruir los roles genéricos tradicionalmente asignados a la mujer y el varón. Por ejemplo, la asociación mujer/madre -el papel más frecuente en los manuales anteriores- es aquí abordado a partir del mito griego de Fedra $^{15}$, poniendo sobre el tapete la dimensión conflictiva de la maternidad. Asimismo, también se retoma un fragmento del texto de la escritora catalana Montserrat Roig, titulado "La madre de Edipo", que reflexiona en la misma línea:

Hijos, a veces me siento igual que una criminal por haberos traídos al mundo. Buscáis un roble en vuestra madre y ella se siente hecha astillas. Tú, Marc, me lames el pecho como si fuese un caramelo de fresa mientras que la directora de la guardería me dice que ya no es prudente que me toques y me acaricies, que te has de separar de mí... [...] Quisiera volverme niña y jugar con vosotros toda la eternidad, que mis pechos se mezclasen con vuestra carne y que vuestras manos recorriesen mi cuerpo como su fuese tierra acabada de labrar. (I994: I65)

No es casual que Link incluyera en su corpus a Roig, una mujer comprometida en la lucha contra el franquismo y el feminismo, que militó en la defensa de los derechos de la mujer. Alguien que, en r98I y a través de un libro titulado El feminismo, denunciaba:

Todavía en nuestros tiempos la palabra feminismo da miedo. Todavía ser "feminista" significa, para algunas mujeres, distanciarse de los hombres, ser una mujer distinta, agresiva, amenazadora de la paz y de la convivencia. (...) Las críticas sobre el feminismo y las feministas son hoy más sutiles y más subterráneas que en los tiempos del sufragismo. (I57)

Pero además de esa inclusión, el gesto transgresor se completa con las siguientes preguntas: “a. ¿Para qué escribe la narradora esta carta a sus hijos? / b. ¿Qué posición corresponde a la madre en el triángulo edípico y cómo vive la narradora esa posición? (1994: 165). Las respuestas no están en ningún solucionario que acompañe ese manual. Se confía en la intervención docente, que podrá seguir problematizando la discusión que suscitan estos interrogantes esenciales mediante sus conocimientos y las interpretaciones de los alumnos.

\footnotetext{
${ }^{5}$ Según este mito, Fedra se enamora de su hijastro, Hipólito. Éste la rechaza, pues una relación entre ellos habría sido incestuosa y Fedra empieza a preocuparse porque Teseo, su marido, no sepa de su secreto amor. Para evitar que Hipólito cuente su versión, Fedra hace creer a Teseo que Hipólito había tratado de ultrajarla. El padre llevado por la cólera, manda a desterrar a su hijo y pide a Poseidón su muerte. Hipólito cumple los designios de Poseidón y muere arrastrado por sus caballos. Finalmente, Fedra se ahorca.
} 
Asimismo, se interpela a los estudiantes a deconstruir también los estereotipos genéricos vinculados al par masculino. Esta vez, la problematización se da mediante la recuperación de un fragmento de "Perceval o el cuento del Grial" del clásico poeta francés Chrétien de Troyes. En el argumento, un hijo recibe los consejos de su madre antes de emprender un viaje a la guerra:

Buen hijo, os quiero dar un consejo (...). Si de cerca o lejos encontráis una dama que tenga necesidad de amparo o a doncella desconsolada, prestadles vuestra ayuda, si ellas os la requieren, pues todo el honor radica en ello. Quien no rinde honor a las damas, su honor debe estar muerto. Servid a damas y doncellas, y seréis honrado en todas partes. (I994: 36 ).

El consejo responde a la doxa de la época. Lo interesante es aquí, la problematización de la misma a través de la pregunta: “QQué es un caballero? ¿Para qué sirve?”, que tiende a visibilizar que el fin último de la caballerosidad es el beneficio del caballero: su honor. Esta problematización continúa aún varias páginas más adelante, cuando es puesta en serie con un fragmento de Cesáreo de Heisterbach, titulado "Dialogus Miracolorum". Allí se pide a los estudiantes que revisen las definiciones de caballero y revean cómo se articulan a una idea de moral, incluso a una época determinada.

Por si fuera poco, aparece, además, tematizada la prostitución. Por ejemplo, a través de un texto de Luis Martín- Santos, titulado "En el prostíbulo", en el que el amante interroga a la prostituta sobre su fórmula para mantener su belleza:

- Dulce servidora de la noche, maga de mi tristeza dolorida, dime: ¿Cómo conseguiste hallar el secreto de la eterna juventud? ¿Quién te permitió a través de tantos besos, conservar el color rojo de tu boca? ¿Cómo es posible que tras tantos catres la carne de tu cuerpo no parezca una esponja empapada en pipí de niño tonto? ¡Habla! Comunica tu secreto a tus admiradores.

- Pues no creas. ¡Toca aquí! -y enseñaba su muslo-. Está duro todavía. Si me hubieras visto antes. (1994: 163)

Pero quizás el punto más álgido del manual se encuentre cuando se tematiza la prostitución homosexual, mediante el texto "Incidentes" de Roland Barthes, incluido en esa suerte de diario llamado Noches de París, en el que el narrador registra sus veladas nocturnas en una ciudad iluminada por el arte, la sofisticación y el sexo. Aunque sea extenso, se transcribe el fragmento íntegramente por la potencia de su valor.

Siempre esta dificultad para trabajar por la tarde. Salí hacia las seis y media, sin rumbo fijo; vi en la calle de Rennes a un nuevo taxi-boy, con el pelo tapándole la cara, y con un pequeño aro en la oreja; como la calle B. Palissy estaba completamente desierta, hablamos un poco; se llamaba François; pero el hotel estaba al completo; le di el dinero, me prometió que volvería una hora 
más tarde, y, naturalmente, no apareció. Me pregunté si me había equivocado de verdad (todo el mundo exclamaría: ¡darle dinero a un taxi-boy por adelantado!), y pensé: puesto que en el fondo no me atraía tanto como eso (ni siquiera me apetecía acostarme con él), el resultado era el mismo: haciendo el amor, o sin hacerlo, a las ocho me habría hallado otra vez en el mismo lugar de mi vida que antes; y como el simple contacto de los ojos, de la palabra, me erotiza, este goce es lo que he pagado. Más tarde, en el Flore, no lejos de nuestra mesa, otro chico, angelical, con los cabellos largos separados por una raya en medio; me mira de vez en cuando; me atrae su camisa muy blanca, abierta, mostrando el pecho; está leyendo Le Monde y bebe Ricar, me parece; no se va, acaba por sonreírme; sus manos grandes desmienten la delicadeza y la dulzura del resto; por ellas intuyo al taxi-boy (acaba saliendo antes que nosotros; le llamo, ya que me sonríe y nos citamos vagamente). Más allá, una familia entera, agitada: niños, tres o cuatro, histéricos (en Francia, siempre): me cansan a distancia. Al volver, me entero por la radio del atentado del IRA contra Lord Mountbatten. Todo el mundo está indignado, pero nadie habla de la muerte de su nieto, un chaval de quince años (I994: I64).

La sola mención del taxi boy posibilita el ingreso al aula de la temática de la homosexualidad e invita a desarticular una serie de convenciones, abre un espacio propicio al advenimiento del otro. Se trata de interceptar políticamente la heterosexualidad como una matriz cultural, como un régimen político de producción y regulación corporal. Y mediante la actividad se apunta directamente a detonar el ideal regulatorio, cuando se pide a los estudiantes que piensen argumentativamente sobre el interrogante: “¿En qué se diferencian el deseo (o al amor) homosexual del deseo (o al amor) heterosexual?" (I994: I64). Esta actividad apunta a una reorientación del discurso, de la historia y de la tradición.

El "sujeto excéntrico" de Teresa de Lauretis (I993) se propone aquí como espacio figurativo crítico que intenta introducir fallas a ese efecto alucinatorio de gestos naturalizados, abrir líneas de fugas, posiciones de resistencia. Al respecto, decía Link en una entrevista que le hiciera Carolina Gruffat:

Enseñar algo relacionado con la literatura, en cualquier curso de todos los niveles escolares, supone un debate sobre el sentido. Al menos en relación con eso debo ser consciente de que (más allá de los protocolos pedagógicos) intervengo en una batalla sobre significaciones. Y, naturalmente, sería ilusorio, en este punto de desarrollo de los estudios culturales y de la pedagogía, presuponer que esa intervención solo afecta a la literatura. Propongo afirmaciones, discuto premisas: siempre, se trata de sostener un discurso sobre la vida y sobre las cosas de este mundo. Cuanto más consciente sea uno de eso que sucede en el aula, mejor preparado estará para evitar arbitrariedades groseras. (2005: 2) 


\section{Reflexiones para seguir pensando}

A partir de r994 se dan una serie de transformaciones económicas que traen como consecuencia la transnacionalización del sector editorial: pequeñas y medianas empresas editoriales se ven absorbidas por grandes grupos multinacionales. Hay un juego de poder allí que se ha ido transformando al ritmo de los procesos políticos, económicos, tecnológicos y culturales (cf. Botto, 2006; Linares, 2009; Tosi, 20I2). En el mercado editorial escolar en particular, la consecuencia más evidente de este proceso de transnacionalización es la mercantilización pedagógica, es decir, un modo de diagramar/escribir/publicar/vender libros particular, que concibe a los manuales como objetos determinados principalmente por factores comerciales. Desde tal perspectiva, la política implementada por las editoriales tendió a potenciar el libro de texto como mercancía; en términos de Martínez Bonafé: "el carácter de mercancía prima sobre el valor de uso pedagógico" (2002: 87).

Esta mercantilización pedagógica en Argentina y durante el arco temporal que va desde 1994 a 2002, se produce en primer momento como consecuencia de la bonanza económica que caracterizó los primeros años de esta etapa. Pero en un segundo momento, también supo aprovechar los años signados por una grave crisis económica: el modo de hacerlo fue mediante el lucro con la desesperación docente, que buscaba el modo de enfrentar los cambios producidos por la introducción de la Ley Federal de Educación y la ausencia del Estado en relación con la transmisión de especializaciones y contenidos que empoderaran a quienes estaban frente al aula. La implementación de los CBC ocasionó una fuerte renovación disciplinar que no estuvo acompañada por capacitaciones para docentes en ejercicio. Los "manuales para docentes" y los "solucionarios" que acompañaban las propuestas de libros de texto para estudiantes son una prueba del rol que estos textos cumplieron: el de formador de formadores (Fernández Reiris, 2005).

Aparecen, entonces, dos grandes cambios ocasionados a partir de la entrada de los consorcios de medios a nuestro país. Por un lado, la rapidez de la renovación de los manuales escolares. Dice Tosi: “La nueva política editorial rompió con el imaginario de un canon pedagógico estable y sólido, e impuso una dinámica de producción de novedades que les garantizaría a las empresas una mayor rentabilidad” (2OI2: 8).

Y por otro lado, es posible reconocer el principio del fin de la autoría individual, que paulatinamente es desplazada por equipos de redactores, cuyos integrantes se convocaban expresamente para ese propósito. Frente a esto, las editoriales diseñaban "series" con características editoriales determinadas, en las que se inscribían distintos títulos y para las que asignaban redactores. Esta posición subordinada de los autores es explícita desde la tapa del manual en la que se advierte que es una obra colectiva creada y diseñada por su departamento editorial.

El caso de Daniel Link y su serie Literator es la excepción a esta norma. Esa propuesta conserva la figura de autor de modo imponente. Pero además, es novedosa en materia de géneros y sexualidades, pues se erige como una propuesta completamente 
transgresora, que interviene desarticulando la cultura heterosexual obligatoria y opera deshaciendo el género. Pero también haciendo foco en las masculinidades. Esto no era muy común, ya que como destacan José Maristany y Jorge Peralta, en el campo:

hubo una especie de distorsión por cuanto la problemática de género se transformó en sinónimo de perspectivas feministas o de estudios de la mujer. De este modo, la masculinidad se mantuvo como lo obvio, aquello que no se interroga y que, por tanto, deviene invisible, natural y universal (2OI7: IO). 


\section{Referencias bibliográficas}

- Bonnet, A. (2008). La hegemonía menemista. El neoconservadurismo en Argentina, 19892001. Buenos Aires: Prometeo.

- Bórtoli, P. (2015). El manual de literatura: conversaciones en torno al mercado editorial escolar. Actas Tercer Coloquio de Avances de Investigaciones del Cedintel: Facultad de Humanidades y Ciencias, Universidad Nacional del Litoral (pp. I2-30). Santa Fe: Universidad Nacional del Litoral.

- Bórtoli, P. (20i6). Con la democracia se come, se educa y se cura. Cuestiones de género y de enseñanza durante el gobierno de Raúl Alfonsín (I983-I989). Actas Cuarto Coloquio de Avances de Investigaciones del Cedintel: Facultad de Humanidades y Ciencias, Universidad Nacional del Litoral (pp. I-3o). Santa Fe: Universidad Nacional del Litoral.

- Bórtoli, P. (2OI7). De libros como zapatos: la mercantilización pedagógica de los manuales de Lengua y Literatura publicados por Santillana (1994-2002). Actas Quinto Coloquio de Avances de Investigaciones del Cedintel: Facultad de Humanidades y Ciencias, Universidad Nacional del Litoral. Santa Fe: Universidad Nacional del Litoral, en prensa.

- Botto, Malena (2006). 1990-2000: la concentración y la polarización de la industria editorial. De Diego, José Luis (dir.). Editores y políticas editoriales en Argentina (1880-200o) (pp. 209-249.). Buenos Aires, Fondo de Cultura Económica.

- Cortés, M. (200I). Los textos. Marcos teóricos y prácticas de enseñanza. En M. Alvarado (coord.). Entre líneas. Teorías y enfoques en la enseñanza de la escritura, la gramática y la literatura. (pp. ІІ3-I58). Buenos Aires: Flacso/Manantial.

- De Lauretis, T. (1993). De mujer a género, teoría, interpretación y práctica feministas en las ciencias sociales. En M. C. Cangiano y L. Dubois (comp.), De mujer a género (pp. 25-32). Buenos Aires: Centro Editor de América Latina.

- Fernández Reiris, A. (2005). La importancia de ser llamado "libro de texto". Hegemonía y control del currículum en el aula. Buenos Aires, Miño y Dávila.

- Galasso, N. (20I4). Historia de la Argentina. Desde los pueblos originarios al tiempo de los Kirchner. Buenos Aires: Colihue.

- Gallardo, A. L. (2007). Entrevista a Rosario Charquero, Editora de Ediciones del Eclipse. El mangrullo, 7(82), [en línea]. Consultado el 2 de septiembre de 2013 enhttp://usuarios. sion.com/mangrullo/mangrullo82.html

- Gerbaudo, A. (2OII). La lengua y la literatura en la escuela secundaria. Santa Fe: Ediciones UNL- Ediciones Homo Sapiens. 
- Gruffat, C. (2005). Daniel Link: Si a algo equivale internet es a la escritura y, por lo tanto, a la cultura letrada. EducAr. Obtenido el 5 de junio desde https://www.educ.ar/recursos/II5812/daniel-link-si-a-algo-equivale-internet-es-a-la-escritura-y-por-lo-tanto-a-lacultura-letrada.

- Linares, M. C. (2009). Las editoriales a fines del siglo XX y su impacto en los libros de lectura escolar. Actas del VIII Congreso Iberoamericano de historia de la Educación Latinoamericana. Contactos, cruces y luchas en la historia de la educación latinoamericana (pp. 225-234). Buenos Aires: RELEE.

- Link, D. (i994). Literator IV. El Regreso. Buenos Aires: del Eclipse.

- Link, D. (20I4). Consulta (por Pamela Bórtoli). Santa Fe: Ediciones UNL.

- Martínez Bonafé (2002) Políticas del libro de texto escolar. Madrid, Morata.

- Mcgee Deutsch, Sandra (20I3). "La Junta de la V". Clase abierta de Teoría Literaria I. Santa Fe: CEDINTEL.

- Molina, C. (2013). Relatos de mercado. Literatura y mercado editorial en el Conosur (19902008). Rosario: Fiesta ediciones.

- Pucciarelli, A. Y Castellani A. (20I4). Los años de la alianza. La crisis del orden neoliberal. Buenos Aires: Siglo XXI.

- Puiggrós, A. (2010). La tremenda sugestión de pensar que no es posible. Luchas por una democracia educativa (1995-2010). Buenos Aires: Galerna.

- Rockwell, E. (2009). La experiencia etnográfica: historia y cultura en los procesos educativos. Buenos Aires: Paidós

- Romero, L. A. (2OOI). Breve historia contemporánea de la Argentina. Buenos Aires: FCE.

- Schirtter, I. (20I4). Consulta (por Pamela Bórtoli). Mimeo.

- Tiramonti, G. (2004). La trama de desigualdad educativa. Mutaciones recientes en la escuela media. Buenos Aires: Manantial.

- Tosi, C. (2009). La edición de libros de texto. Mercado, complejidad del proceso y especificidad de saberes. Espacios 37 [en línea]. Consultado el 9 de septiembre de 2012 en www. filo.uba.ar/contenidos/secretarias/seube/revistaespacios/37.II.pdf 
- Tosi, C. (2OIO). El mercado de los libros de texto. Un análisis sobre el proceso de edición. IX Congreso Argentino de Hispanistas El Hispanismo ante el Bicentenario [en línea]. Consultado el I2 de abril de 2013 en http://www.memoria.fahce.unlp.edu.ar/ library? $\mathrm{a}=\mathrm{d} \& \mathrm{c}=$ eventos $\& \mathrm{~d}=\mathrm{JeviI} 8 \mathrm{O}$

- Tosi, C. (2012). El discurso escolar y las políticas editoriales en los libros de educación media (I960-2005). En Cucuzza, Héctor y Paula Spregelburd, directores. Historia de la lectura en Argentina. Del catecismo colonial a las netbooks estatales (pp. 507-545). Buenos Aires: Editoras del Calderón.

- Tosi, C. (2OI3). Huellas de lo políticamente correcto en libros de texto argentinos: la "modalización autonímica”. Pragmática Sociocultural, I(2), 25 I-28I. [en línea]. Consultada el día 30 de noviembre de $20 \mathrm{O}$ ? en http://museo.bn.gov.ar/media/page/carolina-tosi-ponencia. pdf.

- Tosi, C. (20I5). Discurso pedagógico y políticas editoriales. Un análisis sobre los materiales escolares en la Argentina durante la última década. Jornadas sobre la Historia de las Políticas Editoriales en la Argentina. [en línea]. Consultada el día o9 de septiembre de 2016 en http://museo.bn.gov.ar/media/page/carolina-tosi-ponencia.pdf.

- Venturini, S. (20I4). Micropolíticas de la edición y de la traducción: el catálogo de Colección Chapita. XI Jornadas Nacionales De Literatura Comparada. Buenos Aires: Cuadernos Lírico. 